\title{
Edward Angle (1855 to 1930) ...the father of modern Orthodontics
}

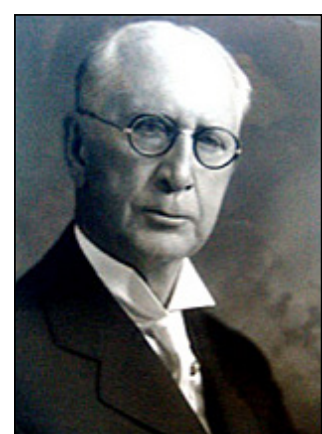

A man of considerable complexity, Edward Angle combined a fierce determination to achieve perfection with an uncompromising demand that all those around him should also be imbued with the same commitment.

It was a combination that enabled Angle to become an icon in Dentistry, for he is widely regarded as the father of modern Orthodontics and his concepts and appliances still provide the foundation for much of the discipline today.

He was born in Herrick, Pennsylvania on June $1^{\text {st }} 1855$. Abandoning the option to continue the family tradition of farming, the young Angle apprenticed himself to a dentist, then enrolled as a student in the Pennsylvania College of Dental Surgery. He developed an abiding interest in the challenges of malocclusion and became known for his innovative views on corrective treatment.

Appointed as teacher in Orthodontics at St Louis and Washington Universities where the subject was a minor component of the Department of Prosthetics, he became convinced that the discipline warranted separate educational facilities.

That became a lifelong objective and indeed resulted in the first institution devoted exclusively to the teaching of Orthodontics... recognised by the State of California in 1924 and designated as The Edward H Angle College of Orthodontia.

Angle devised the classification of malocclusion known eponomously as the Angle system... a contribution with which all students of Dentistry are familiar. He was a tireless inventor of appliances and instruments and wrote many papers describing these advances.

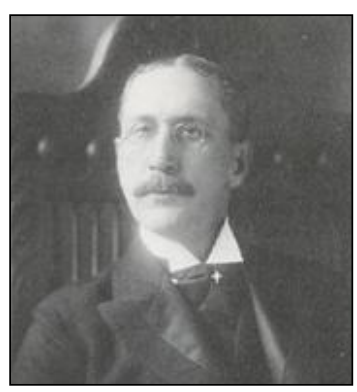

Never bashful about his ideas, he energetically advocated their application... one of his papers was entitled "The latest and the best in Orthodontic Appliances".

He developed the Pin and Tube appliance, the expansion $\mathrm{E}$ arch, the Ribbon arch and, in 1925, his crowning contribution, the Edgewise appliance. This last technique has been the basis for the evolution of the sophisticated brackets in use today. The biological principles which he recognised and on which he relied are those currently guiding the profession.

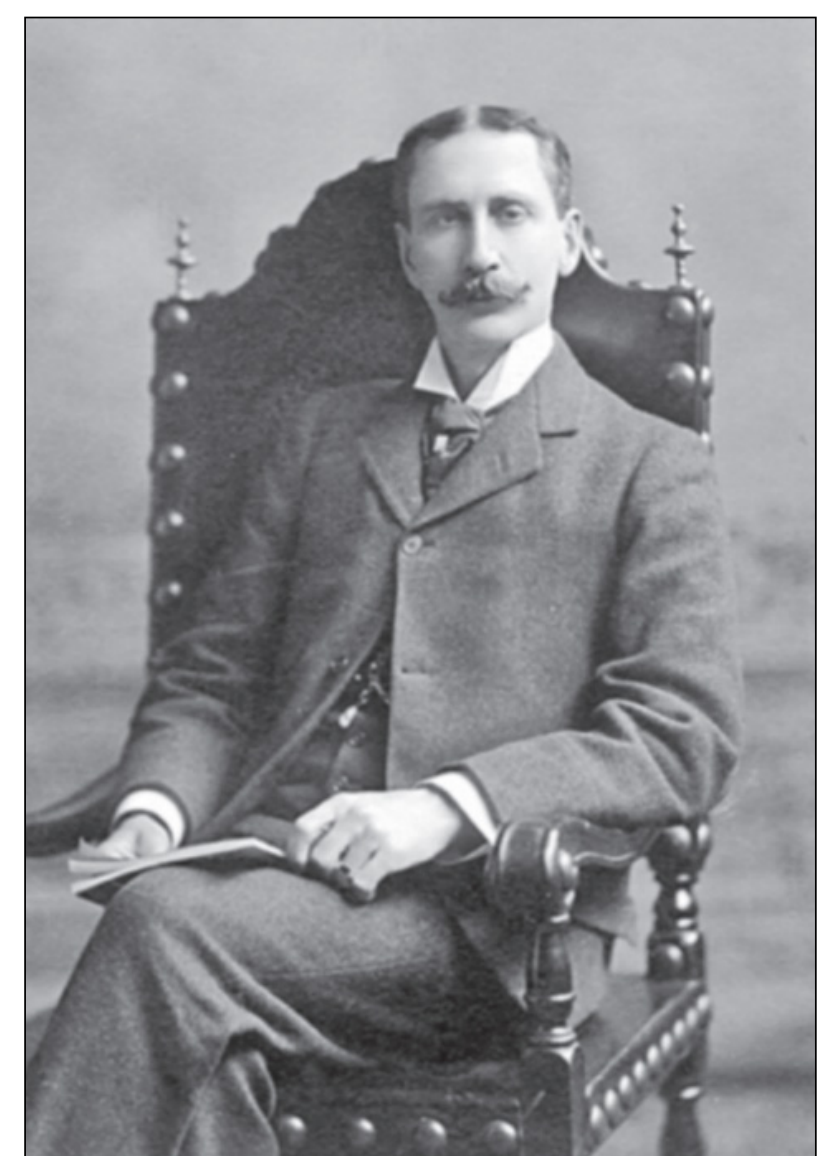

Edward $\mathrm{H}$ Angle was trained as a dentist, but made orthodontics his speciality and dedicated his life to standardizing the teaching and practice of Orthodontics.

Often dismissive of any who failed to meet his standards of commitment, ethics and ability, he expected his students to strive continuously towards the selfdiscipline he considered essential to approach perfection.

Students of today will be intrigued to learn that Angle instructed his students to clean the surgeries and workplaces, scrubbing the floors and sweeping the offices!

The influence of this extraordinary man has been worldwide. Orthodontists the world over have figuratively sat at the feet of this pioneer, absorbing the philosophy, the commitment and the principles which he embodied. The message goes much further than the practice of the profession... he expected the highest ideals in every aspect of life. 